\title{
Reviews
}

Ashu Mohammad' / Priyanka Thakur² / Rakesh Kumar' / Sharanpreet Kaur ${ }^{3}$ / Reena V. Saini' / Adesh K. Saini ${ }^{1,4}$

\section{Biological markers for the effects of yoga as a complementary and alternative medicine}

\author{
${ }^{1}$ Faculty of Applied Sciences and Biotechnology, Shoolini University of Biotechnology and Management Sciences, 173229, \\ Solan, Himachal Pradesh, India, E-mail: sainiade@gmail.com \\ ${ }^{2}$ Faculty of Basic Sciences, Shoolini University of Biotechnology and Management Sciences, Solan, Himachal Pradesh, India \\ ${ }^{3}$ Orbit Biotech Pvt. Ltd., Mohali, Chandigarh, Punjab, India \\ ${ }^{4}$ Center of Research on Himalayan Sustainability and Development, Shoolini University of Biotechnology and Management \\ Sciences, Solan, Himachal Pradesh, India, E-mail: sainiade@gmail.com
}

\begin{abstract}
:
From the last few decades, there are increasing incidences of disorders like premature aging, cardiovascular disease, multiple sclerosis, fibromyalgia, and Alzheimer's disease In addition to medication, researchers have found that yoga, a mind-body therapy, can be used as an alternative medicine. Yoga combines specific physical postures, breathing techniques, relaxation and meditation that improve mental and physical health of the body. The purpose of this review is to collate the research evidences claiming health benefits of performing traditional yogic practices. What are the biological and other reliable indicators to suggest that doing asanas, pranayama, and meditation could reduce or treat wide range of life style disorders are discussed. Importantly, these indicators are otherwise used to assess the severity of disorders. In many of the study it has been shown that yoga improves the redox health of body whose imbalance has been well proven to cause many health complications. The impact of yoga on neurodegenerative diseases have revealed that it reverses memory loss, reduce anxiety, depression and stress, the biological indicators of disease. However, most studies have several limitations and therefore further research into yoga is needed to validate these findings.
\end{abstract}

Keywords: alternative medicine, lifestyle disorders, yoga

DOI: 10.1515/jcim-2018-0094

Received: June 7, 2018; Accepted: October 9, 2018

\section{Introduction}

Yoga is a physical and mental practice that originated in India over 2,000 years ago [1]. The term yoga is derived from the Sanskrit word yuj, meaning "to join," and symbolizes the union of the body with the consciousness in the mind and spirit [2]. Yoga is a mind body intervention that combine specific physical postures (asanas), breathing techniques (pranayama), relaxation and meditation to encourage union of mind and body[2,3]. Yoga consists of eight limbs: yama (ethical behavior), niyama (personal behavior), asana (physical posture), pranayama (breath regulation), pratyahara (sensory inhibition), dharana (concentration), samadhi (intergration), dhyana (meditation). Yogic practice of these limbs simultaneously leads to higher state of ethics, spirit and healing [4].

Regular yoga exercise leads to improved health and well-being. In recent years' yoga has been the subject of research as a therapeutic measure to prevent or treat medical conditions such as stress, insomnia, obesity, anxiety, diabetes, hypertension, oxidative stress, glucose tolerance, dyslipidemia, neurodegenerative disease and coronary heart disease [5-7]. The practice of yoga asanas and pranayama helps in controlling the total serum cholesterol LDL, VLDL, and triglycerides [7, 8]. Yoga has also been found to improve overall health and reduce self-reported symptoms in urologic disorder and chronic back pain [9-11]. It would be important to understand the gained improvements owing to yoga and their correlation with the changes in biomarkers.

Adesh K. Saini is the corresponding author.

(c) 2019 Walter de Gruyter CmbH, Berlin/Boston.

This content is free. 


\section{Antioxidant nature of yoga}

Oxidative stress is a result of increased levels of reactive oxygen species (ROS) and reactive nitrogen species (RNS) over antioxidants and leads to the damage of different biomolecules like DNA, protein, lipids which further contribute to diseases including cancer, cardiovascular disease, neurodegenerative disorders and aging [12-15]. For instance, generation of ROS leads to the overexpression of $J U N$, an oncogene which is involved in lung cancer [16]. To respond to deleterious effects of oxidative stress it is very crucial to maintain the required level of antioxidants in the body. For this cells produce various antioxidant enzymes like superoxide dismutase (SOD), catalase, peroxiredoxins (PRXs), malondialdehyde (MDA) etc. (Table 1). 


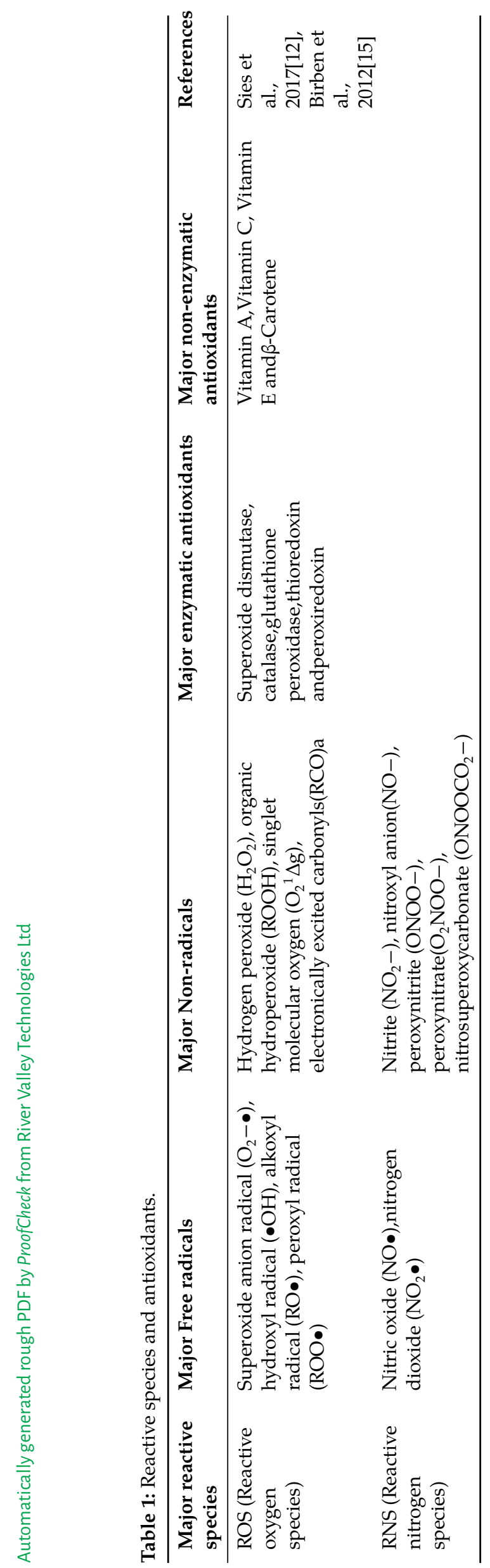


Level of glutathione (GSH) is a major non-enzymatic intracellular marker of antioxidant status [4]. The level of Glutathione increased significantly from $235.3+16.9 \mathrm{nmol} / \mathrm{L}$ to $331.7+37.6 \mathrm{nmol} / \mathrm{L}$ among male volunteers of Indian navy who practiced yoga [17]. A Pilot study among pre-diabetics showed no significant difference between the baseline value $7.8 \pm 2.5$ and the final value $8.2 \pm 2.4$ after 3 -months of yoga practice [18]. Whereas yoga practices (Yogasana, pranayama and meditation) for three months resulted in 2.1 fold increase in GSH among healthy university students [19].

GSH can be oxidized to glutathione disulfide (GSSG) with the action of glutathione peroxidase (GPX) in response to oxidative stress and Glutathione reductase (GR) recycle GSSG to its reduced state using reduced nicotinamide adenine dinucleotide phosphate (NADPH) as hydrogen donor. The ratio of GSH/GSSG, also known as the glutathione redox ratio (GRR) is a sensitive indicator of oxidative stress and has been shown to increase significantly $(\mathrm{p}<0.001)$ after 3 months of yoga practice (Yogasana, pranayama, and meditation) [17, 20].

Glutathione peroxidase (GPx) glutathione reductase (GR) and glutathione S-transferase (GST), SOD and catalase are the enzymatic antioxidant components that protect against oxidative stress. Studies on healthy individuals showed that activities of GPx, and GST were significantly increased after 3 months yoga practice $(p<0.05)$. Whereas no significant change was observed in glutathione reductase activity $(p<0.05)[19]$.

In another study conducted on physically active males from Indian Air Force, activity of glutathione Stransferase increased significantly $(\mathrm{p}<0.001)$, while GPx activity decreased significantly $(\mathrm{p}<0.001)$. GR activity also increased significantly $(\mathrm{p}<0.05)$ following 3 months yogic practice [17].

Superoxide radical $\left(\mathrm{O}_{2}^{-\bullet}\right)$ is highly active oxidant however, SOD detoxifies superoxide radical $\left(\mathrm{O}_{2}^{-\bullet}\right)$ by converting it to hydrogen peroxide and $\mathrm{O}_{2}$; further, catalase and GSH detoxifies hydrogen peroxide into water and alcohol [21]. The activity of SOD increases significantly after following 3 months yoga practice among healthy individuals [17] whereas, Hegde et al documented significant decrease in SOD activity (unit/gmHb) after 3 months of yogic practices (Yogasana, shavasana and pranayama) $4721.0 \pm 1263.0$ (3992.0-5450) vs. 4340.0 \pm 978.0 (3776.0-4905.0) among pre-diabetes patients [18]. There was significant 4.65\% increase in SOD activity and $0.09 \%$ in catalase among patients with end-stage renal disease on hemodialysis who practiced hatha yoga for 4-months [22].

Vitamin $C$ and vitamin E both are potent components of an antioxidant defense system. The levels of vitamin $C$ and vitamin $E$ were increased significantly $(p<0.001)$ following yogic practices [17].

MDA is the end product of lipid peroxidation, which is stimulated by increased level of ROS. Moreover, increased level of MDA induces various cellular reactions which results in destruction of DNA and protein [23, 24]. A study done among the healthy yoga practitioners has shown significant reduction in the level of MDA as compared with the control group $(p<0.01)$ [25]. In another study done among prediabetic patients, 3-month practice of yogasanas and pranayama and shavasana resulted in significant reduction in malondialdehyde level $(\mathrm{p}<0.001)[18]$.

A study conducted among hypertensive individuals, has shown that the level of MDA was significantly reduced $(\mathrm{p}<0.05)$ among patients who performed yoga (Yogasana and Pranayama), the decrease was by $4.0 \%$ after four months of intervention $(p=0.096)$ [25]. Pal et al also observed Non significant decrease in both the control group (8.56 \pm 0.63 to $8.38 \pm 0.60)$ and yoga group $(7.78 \pm 0.50$ to $6.01 \pm 0.46)$ among healthy males [17] This decrease in the MDA level may be due to decrease of lipid peroxidation via increased antioxidant level [26].

Total antioxidant status (TAS) is also an important antioxidant marker. The level of TAS increased significantly $(p<0.001)$ following 3 months of yogic practice which indicates a marked improvement in the overall cellular antioxidant level [17].

The above mentioned studies involved different types of participants; healthy as well as individual suffering from various health conditions. The yoga interventions and the duration of the program were also varied. Majority of studies reported that practicing yoga was helpful in increasing the level of GSH, GSH/GSSH, total antioxidants status (TAS), vitamin C, vitamin E, glutathione reductase (GR) activity, catalase and GST activity and reducing the level of GSSG and MDA (Table 2). 


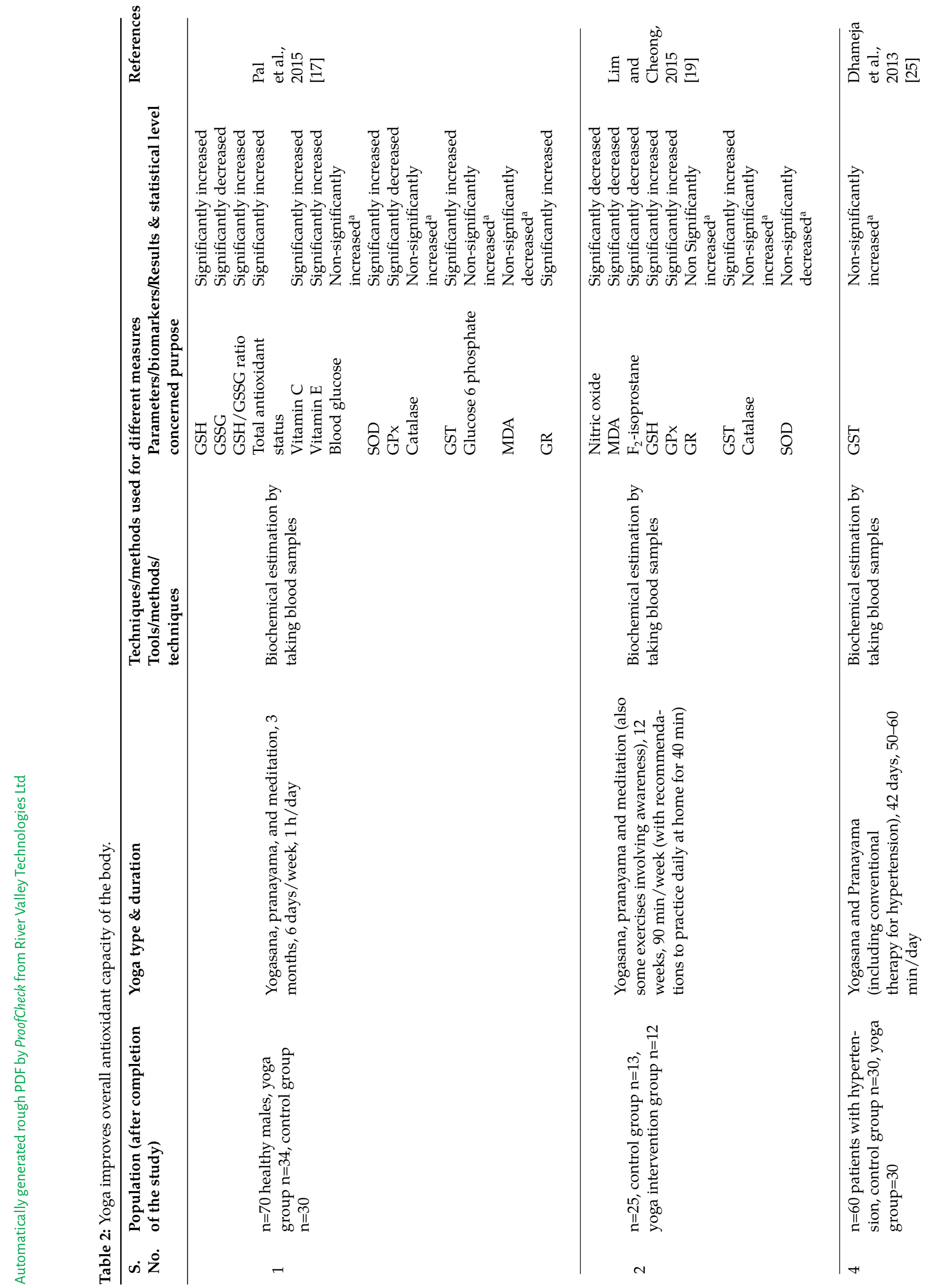




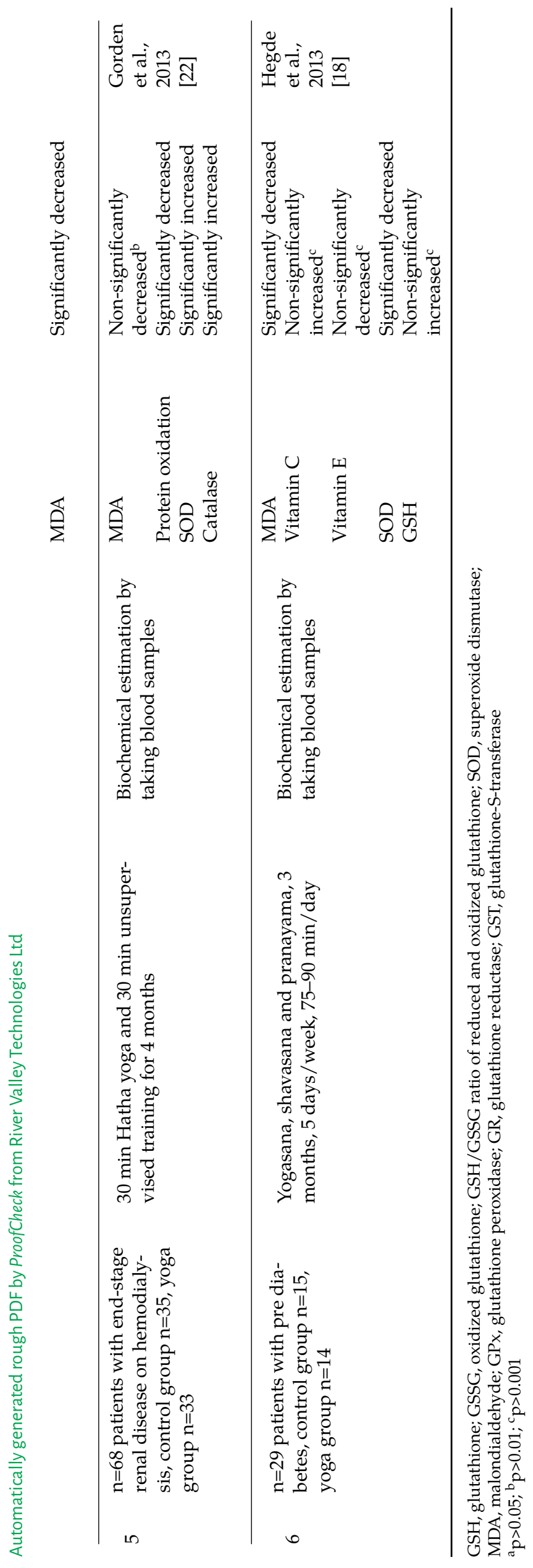




\section{Improvement of cardiovascular health due to yogic practices}

People suffering from mood disorders have higher risk of cardiovascular disease due to less cardiorespiratory coupling and autonomic dysfunction [27-29]. Anxiety which is common in mood disorders is known to change the breathing patterns which evokes increase in tidal volume, respiratory rate and decrease in respiratory time amongst healthy people [30,31]. Yoga has been shown to help in improved breathing function and coronary artery calcium (CAC), increased adaptation to hypoxia and improved mood [32-34]. Sudarshan Kriya yoga (SKY) which is known to be helpful in depression, anxiety and stress has now also been reported to increase the spontaneous respiratory coupling and cardiac autonomous control in patients with anxiety and stress disorders which decreases the risk of cardiovascular disease in such patients (Table 3) [39-41]. 


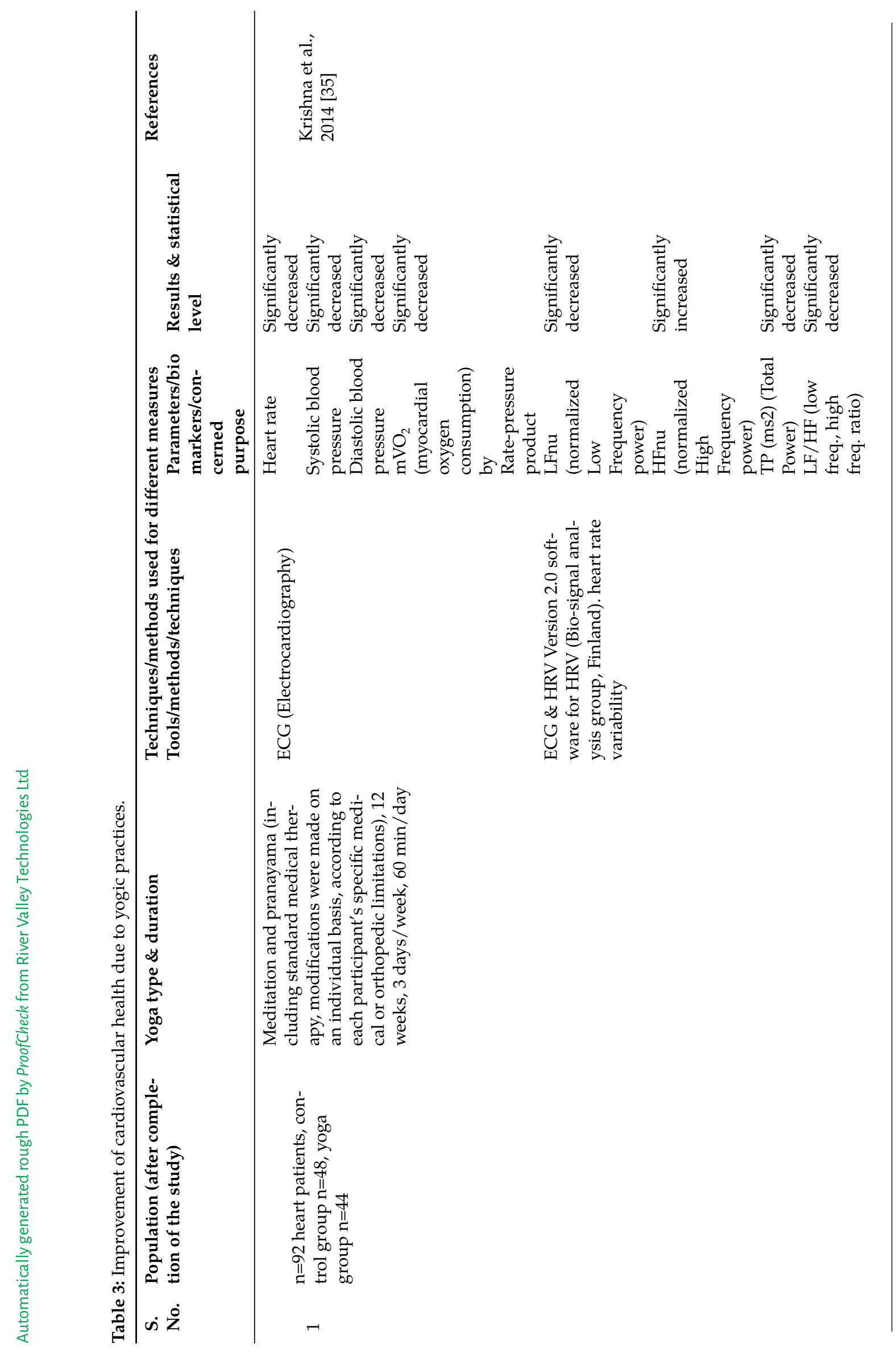




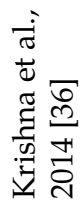

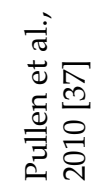

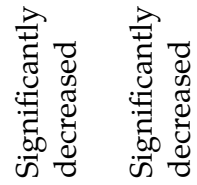

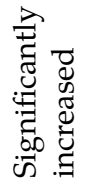<smiles>C1[C@@H]2[C@H]3C[C@H](C3)[C@@H]12</smiles>

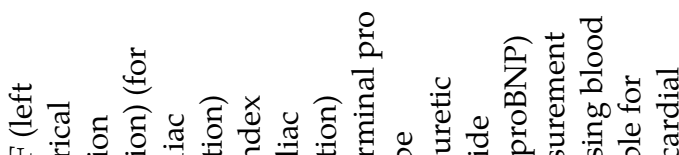

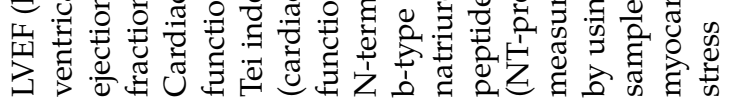

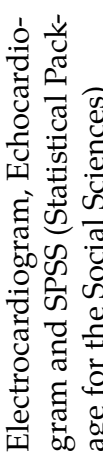
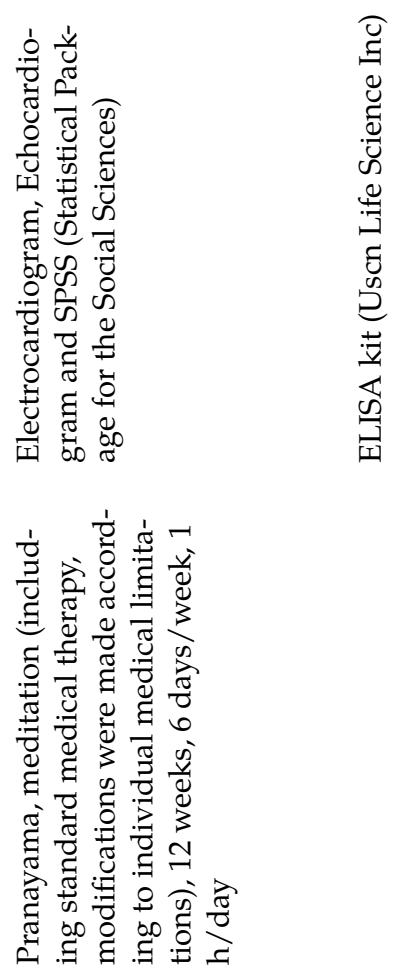

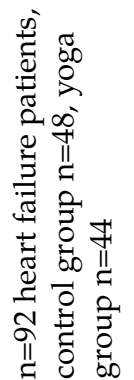

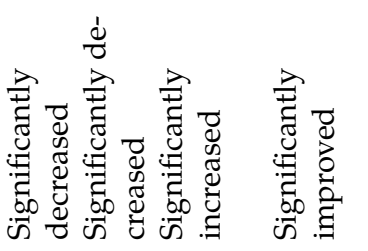

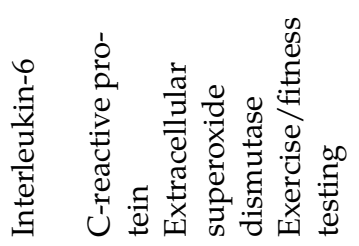

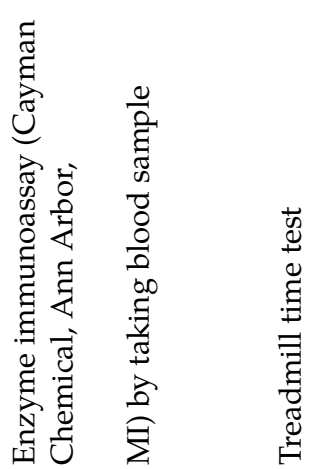

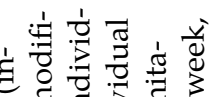

疍

(둥

दै 00 o

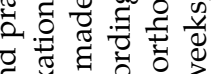

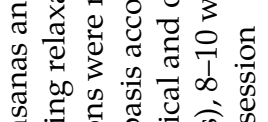

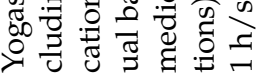

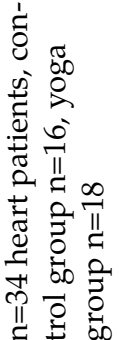

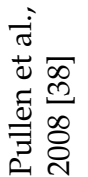

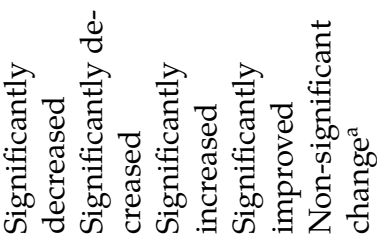

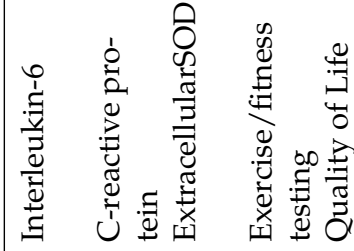

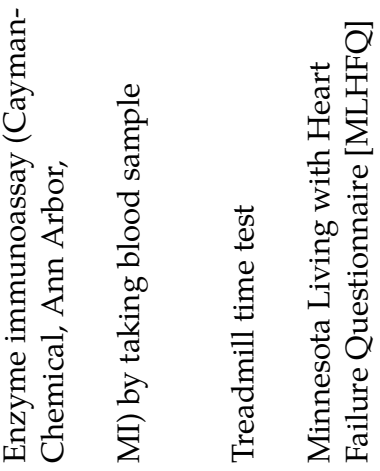

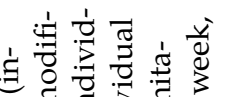

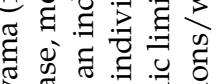

क्षै

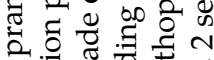

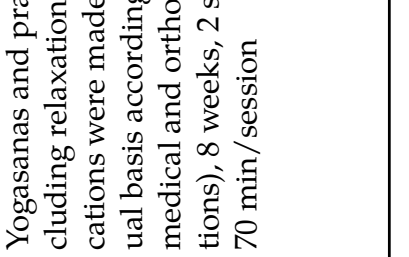

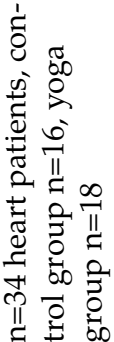




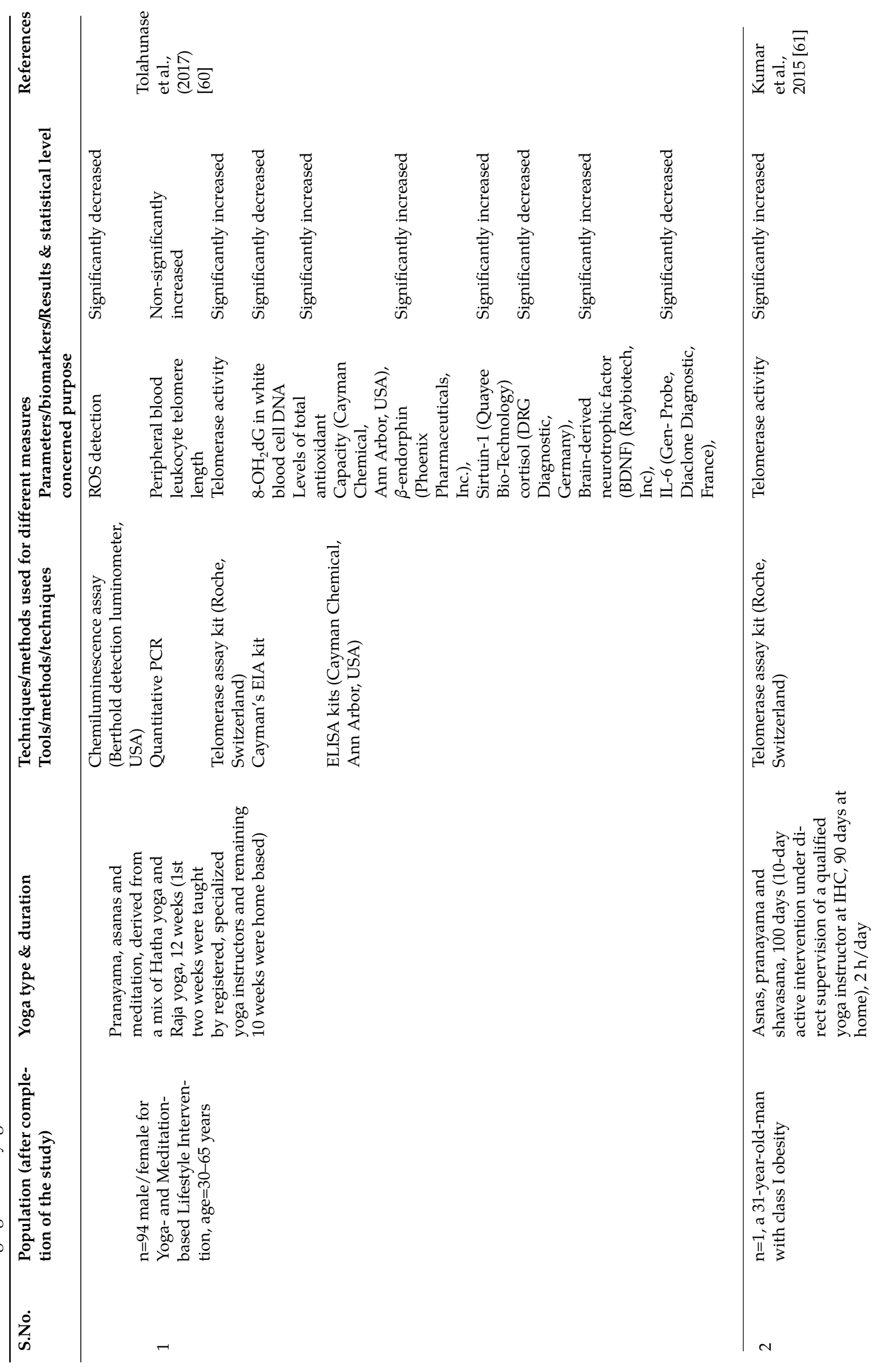




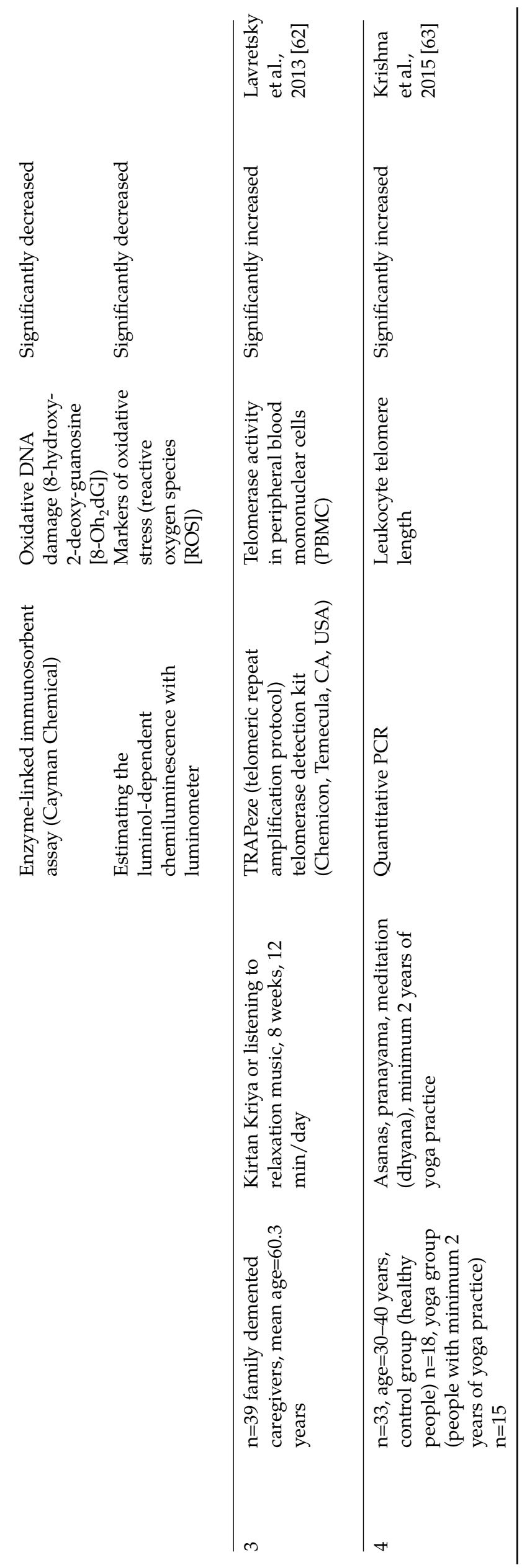


A study done among the heart failure (HF) patients has shown that 12 weeks of yoga therapy (Meditation and pranayama) along with standard medical therapy resulted in a significant decrease in Heart Rate $(H R)(p<0.001)$, Rate pressure product (RPP) $(p<0.001)$, systolic blood pressure $(p<0.01)$, diastolic blood pressure $(\mathrm{p}<0.001)$, normalized Low Frequency power (LFnu) $(\mathrm{p}<0.001)$, low freq., high freq. ratio (LF/HF ratio) $(p<0.001)$ and a significant increase in normalized High Frequency power $(H F n u)(p<0.001)$ [35].

Another study among heart failure patients has shown significant improvement in left ventrical ejection fraction (LVEF) and Tei index after 12 weeks of yoga therapy (Meditation and pranayama). LVEF was increased from $38.93 \pm 5.1$ to $52.96 \pm 6.01(36.88 \%$ in the yoga group (YG) and $16.9 \%$ in the control group (CG) $(\mathrm{p}<0.01)$ and Tei index was reduced from $0.54 \pm 0.85$ to $0.38 \pm 0.03(27.87 \%$ in the $Y G)$ and $2.79 \%$ in the CG (p<0.01). A significant decrease $63.75 \%$ in the YG and $10.77 \%$ in the CG $(p<0.01)$ in N-terminal pro b-type natriuretic peptide (NT-proBNP) level, which was also reported in Yoga Group (pre: $3965.48 \pm 1365.08$, post: $1395 \pm 997.08$ ) [36]. These results indicate that 12-week yoga therapy offered additional benefits to standard medical therapy for Heart Failure patients by improving cardiac function, parasympathetic activity while reducing the sympathetic activity and myocardial stress [36, 42, 43].

Pro-inflammatory markers such as interleukin-6 (IL-6), high sensitivity C-reactive protein (hs-CRP) and extra cellular superoxide dismutase (EcSOD) have been associated with unfavorable cardiovascular outcomes in heart failure [42]. Increased levels of IL-6 and CRP have been adversely associated with HF [43, 44] and ECSOD activity has been correlated with endothelium-mediated, flow-dependent vasodilatation [45]. Pullen et al showed that after yogic intervention (Yogasanas and pranayama) there was a significant reduction in serum level of IL-6 (19.6 \pm 2.5 to $16.0 \pm 2.1 \mathrm{mg}$. dL $\left.\mathrm{dL}^{-1}: \mathrm{p}<0.001\right)$ and hs-CRP $\left(2.4 \pm 0.58\right.$ to $\left.1.9 \pm 0.4 \mathrm{mg}^{\mathrm{dL}} \mathrm{dL}^{-1}: \mathrm{p}<0.001\right)$. Levels of EC-SOD increased from $509 \pm 71.9$ to $610 \pm 86.2 \mathrm{U}_{\mathrm{UmL}}^{-1}: \mathrm{p}<0.001$ ) [37] and the results showed consistency with the earlier studies of Pullen et al which showed statistically significant reductions in serum levels of inflammatory markers: IL-6 and hs-CRP and an increase in EC-SOD in the Yoga (Yogasanas and pranayama) treatment group (all $\mathrm{p}<0.005)$ [38].

\section{Anti-ageing impacts of yoga}

Aging is sequential change in an organism, or a decline of physiological goodness that leads to an increased threat of disease, debility, organism's inability to habituate to metabolic stress and ultimately death [46]. Ageing at genomic level is largely the result of DNA damage caused by ROS, chemicals like benzo[a]pyrene, UV/IR radiations, spontaneous hydrolytic reactions, DNA replication errors which leads to various genetic lesions which includes point mutations, gene disruption, telomere shortening, translocations etc. Damage caused by these lesions is repaired by DNA repair mechanisms for example base excision repair (BER), nucleotide excision repair (NER), non-homologous end joining (NHEJ) [47-51]. Excessive DNA damage and insufficient DNA repair mechanism favors the aging process.

Recently published studies demonstrated that aging is associated with telomerase activity and telomere length and maintaining telomere length is important to prevent cellular senescence [46]. Telomere is repetitive nucleotide sequence at each end of the chromosome which protects chromosome from damage and prevents the fusion with adjoining chromosomes and these ends of chromosomes are vulnerable to age-related decay [5254]. The length of telomere gets shorten with ageing and age-related diseases. Telomeres are found to be prone to inflammation and oxidative stress which can further promote telomere shortening, hence ageing. Loss of telomere-protective sequences due to deprivation of human telomerase reverse transcriptase (hTERT) activity lead to aging in humans and mice, whereas aging can be delayed in mice by reactivation of telomerase [46, $55,56]$. Telomeric DNA is protected by a six-subunit protein called Shelterin which bounds telomere prevents the ingression of DNA repair proteins to the telomeres [57]. Lack of shelterin induces telomere uncapping, non-homologous end joining, senescence and/or apoptosis [58, 59].

Several studies have provided significant evidence of the impact of yoga-intervention on telomerase activity and telomere length.

Tolahunase et al studied the effect of a 12 week Yoga (Yogasana, pranayama, and meditation) Based Lifestyle Intervention on both cardinal and metabotropic biomarkers associated with cellular aging. The findings showed a significant reduction in the mean levels of 8-hydroxy 2 deoxyguanosine $\left(8-\mathrm{OH}_{2} \mathrm{dG}\right)$ and $\mathrm{ROS}$ while enhancement in the mean levels of total antioxidant capacity (TAC) and telomerase activity (all values $\mathrm{p}<0.05)$. The mean level of telomere length was increased, but this result was not significant $(\mathrm{p}=0.069)$. The metabotrophic blood biomarkers associated with cellular aging are cortisol, $\beta$-endorphin, IL-6, Brain-derived neurotrophic factor (BDNF), and sirtuin-1. The mean levels of cortisol and IL-6 were significantly reduced and mean levels of $\beta$-endorphin, BDNF, and sirtuin-1were significantly increased (all values $\mathrm{p}<0.05$ ) [60] (Table 4).

A study by Kumar et al showed there was an enhancement in telomerase activity and decrease in oxidative stress (ROS) and DNA damage marker $\left(8-\mathrm{OH}_{2} \mathrm{dG}\right)$ by yoga (Asnas, pranayama, shavasana) lifestyle inter- 
vention. The yoga program included asanas (postures), pranayama (breathing exercises), stress management, group discussions, lectures, and individualized advice [61] (Table 4).

Lavretsky et al measured the effect of 12 min kirtan kriya and listening to relaxation music on telomerase activity using telomeric repeat amplification protocol (TRAPeze) telomerase detection kit, and observed a significant $43 \%$ increase in telomerase activity which leads to increase in length of telomeres and ultimately delay aging [62] (Table 4).

A similar study by Krishna et al reported that leukocyte telomere length (LTL) was significantly increased $(p<0.001)$ in the yoga group by yogic actions like Asanas (bodily/tangible positions), Pranayama, Dhyana (meditation) and was measured by quantitative PCR [63] (Table 4).

\section{Limitations}

In many case studies the control group was missing, so it is very difficult to suggest whether the results are due to the yogic intervention or not [60-62]. In some studies, yogic intervention along with medication, physical exercise, or relaxing music were employed to analyze the changes in biological indicators and so it is difficult to assess the impact of yoga alone $[19,22,25,37,38,62,63]$. While in some studies the focus was to establish cause and effect relationship without going into the details of mechanism.

\section{Conclusions}

Taken together, evidences are gaining which suggest that yogic interventions improve overall health of body which can be analyzed by assessing the levels of biological indicators. These indicators can also help to determine which practice could be employed to have greater impact in curing a specific ailment or getting a specific benefit. These studies would be important for people who are predisposed to diseases due to genetic or environmental factors. Further studies, with proper control groups, can be taken to analyze the impact of diet or change in lifestyle could further add value to the yogic interventions. Another interesting area of study could be to determine the relation between ethnic/genetic diversity, economic variability, and environmental factors and their impact on the final outcome of yogic practices.

Author contributions: All the authors have accepted responsibility for the entire content of this submitted manuscript and approved submission.

Research funding: This work was funded by grants to from the Department of Science and Technology, Government of India Grant [Int/NZ/P-2/13] to AKS. RVS is supported by Department of Biotechnology, Govt. of India (BT/PR9613/MED/30/1260/2013) and Centre of Research on Himalayan Sustainability and Development, Shoolini University of Biotechnology and Management Sciences for providing facilities and financial support (SURF/CRSHT/2016-020). PT is supported by DST-INSPIRE fellowship (IF170502).

Employment or leadership: None declared.

Honorarium: None declared.

Competing interests: The funding organization(s) played no role in the study design; in the collection, analysis and interpretation of data; in the writing of the report; or in the decision to submit the report for publication.

\section{References}

[1] Birdee CS, Yeh GY, Wayne PM, Phillips RS, Davis RB, Gardiner P. Clinical applications of yoga for the pediatric population: a systematic review. Acad Pediatr. 2009;9:212-20.

[2] Chong CS, Tsunaka M, Tsang HW, Chan EP, Cheung WM. Effect of yoga on stress management in healthy adults: a systematic review. Altern Ther Health Med. 2011;17:32-8.

[3] Satchidananda SS. Sādhana Pāda. In: Satchidananda SS, editor(s). The yoga sutras of patanjali, 15th ed ed.Buckingham, United States of America: Integral Yoga Publications, 2010; 131-150.

[4] Pal R, Gupta N. Yogic practices on oxidative stress and of antioxidant level: a systematic review of randomized controlled trials. ] Complement Integr Med. 2017. DOI: 10.1515/jcim-2017-0079 
[5] Khalsa SBS. Yoga as a therapeutic intervention: a bibliometric analysis of published research studies. Indian ] Physiol Pharmacol. 2004;48:269-85.

[6] Penman S, Cohen M, Stevens P, Jackson S. Yoga in Australia: results of a national survey. Int ] Yoga. 2012;5:92.

[7] Taneja DK. Yoga and Health. Indian ] Community Med. 2014;39:68-72.

[8] Balaji PA, Smitha VR, Sadat AS. Effects of yoga - pranayama practices on metabolic parameters and anthropometry in type 2 diabetes. Int Multidiscip Res ]. 2011;1:1-4.

[9] Lipton L. Using yoga to treat disease: an evidence-based review. JAAPA. 2008;21:34-41.

[10] Groessl E], Weingart KR, Aschbacher K, Pader L, Naxi S. Yoga for veterans with chronic low-back pain. ] Altern Complement Med. 2008;14:1123-29.

[11] Ripoll E, Mahowald D. Hatha yoga therapy management of urologic disorders. World ] Urol. 2002;20:306-09.

[12] Sies H, Berndt C, Jones DP. Oxidative stress. Annu Rev Biochem. 2017;86:25.1-25.34.

[13] Valko M, Leibfritz D, Moncol ], Cronin MT, Mazur M, Telser ]. Free radicals and antioxidants in normal physiological functions and human disease. Int] Biochem Cell Biol. 2007;39:44-84.

[14] Tandon VR, Sharma S, Mahajan A, Bardi CH. Oxidative stress: a novel strategy in cancer treatment. JK Science. 2005;7:1-3.

[15] Birben E, Sahiner UM, Sackesen C, Erzurum S, Kalayci O. Oxidative stress and antioxidant defense. World Allergy Organ ]. $2012 ; 5: 9$.

[16] Szabo E, Riffe ME, Steinberg SM, Birrer M], Linnoila RI. Altered c]UN expression: an early event in human lung carcinogenesis. Cancer Res. 1996;56:305-15.

[17] Pal R, Singh SN, Halder K, Tomer OS, Mishra AB, Saha M. Effects of yogic practice on metabolism and antioxidant-redox status of physically active males. J Phys Act Health. 2015;12:579-87.

[18] Hegde SV, Adhikari P, Shetty S, Manjrekar P, D'Souza V. Effect of community-based yoga intervention on oxidative stress and glycemic parameters in prediabetes: a randomized controlled trial. Complement Ther Med. 2013;21:571-6.

[19] Lim SA, Cheong K]. Regular yoga practice improves antioxidant status, immune function, and stress hormone releases in young healthy people: a randomized, double-blind, controlled pilot study. J Altern Complement Med. 2015;21:530-38.

[20] Sinha S, Sn S, Yp M, Us R. Improvement of glutathione and total antioxidant status with yoga. Altern Complement Med. 2007;13:108590.

[21] Powers SK, Jackson M]. Exercise-induced oxidative stress: cellular mechanisms and impact on muscle force production. Physiol Rev. 2008;88:1243-76.

[22] Gordon L, McGrowder DA, Pena YT, Cabrera E, Lawrence-Wright MB. Effect of yoga exercise therapy on oxidative stress indicators with end-stage renal disease on hemodialysis. Int ] Yoga. 2013;6:31-8.

[23] Gawl S, Wardas M, Niedworok E, Wardas P. Malondialdehyde (MDA) as a lipid peroxidation marker. Wiad Lek. 2004;57:453-5.

[24] Ayala A, Munoz MF, Arguelles S. Lipid peroxidation: production, metabolism, and signaling mechanisms of malondialdehyde and 4hydroxy-2-nonenal. Oxid Med Cell Longev. 2014;2014:360438.

[25] Dhameja K, Singh S, Mustafa MD, Singh KP, Banerjee BD, Agarwal M, et al. Therapeutic effect of yoga in patients with hypertension with reference to CST gene polymorphism. J Altern Complement Med. 2013;19:243-49.

[26] Cordon LA, Morrison EY, McCrowder DA, Young R, Fraser YT, Zamora EM, et al. Effect of exercise therapy on lipid profile and oxidative stress indicators in patients with type 2 diabetes. BMC Complement Altern Med. 2008;8:21.

[27] Bär K], Schuhmacher A, Höfels S, Schulz S, Voss A, Yeragani VK, et al. Reduced cardio-respiratory coupling after treatment with nortriptyline in contrast to S-citalopram. J Affect Disord. 2010;127:266-73.

[28] Berger S, Schulz S, Kletta C, Voss A, Bär K]. Autonomic modulation in healthy first- degree relatives of patients with major depressive disorder. Prog Neuropsychopharmacol Biol Psychiatry. 2011;35:1723-28.

[29] Voss A, Boettger MK, Schulz S, Gross K, Bär K]. Cender-dependent impact of major depression on autonomic cardiovascular modulation. Prog Neuropsychopharmacol Biol Psychiatry. 2011;35:1131-8.

[30] Mador M], Tobin M]. Effect of alterations in mental activity on the breathing pattern in healthy subjects. Am Rev Respir Dis. 1991;144:481-7.

[31] Masaoka Y, Homma I. Anxiety and respiratory patterns: their relationship during mental stress and physical load. Int] Psychophysiol. 1997:27:153-9.

[32] Santaella DF, Devesa CR, Rojo MR, Amato MB, Drager LF, Casali KR, et al. Yoga respiratory training improves respiratory function and cardiac sympathovagal balance in elderly subjects: a randomised controlled trial. BM] open. 2011;1:e000085.

[33] Bernardi L, Passino C, Spadacini G, Bonfichi M, Arcaini L, Malcovati L, et al. Reduced hypoxic ventilatory response with preserved blood oxygenation in yoga trainees and Himalayan Buddhist monks at altitude: evidence of a different adaptive strategy?. Eur ] Appl Physiol. 2007;99:511-8.

[34] Pascoe MC, Bauer IE. A systematic review of randomised control trials on the effects of yoga on stress measures and mood. ] Psychiatr Res. 2015;68:270-82.

[35] Krishna BH, Pal P, Pal CK, Balachander ], Jayasettiaseelon E, Sreekanth Y, et al. Effect of yoga therapy on heart rate, blood pressure and cardiac autonomic function in heart failure. J Clin Diagn Res. 2014;8:14.

[36] Krishna BH, Pal P, Pal CK, Balachander ], Jayasettiaseelon E, Sreekanth Y, et al. A randomized controlled trial to study the effect of yoga therapy on cardiac function and N terminal Pro BNP in heart failure. Integr Med Insights. 2014;9:1.

[37] Pullen PR, Thompson WR, Benardot D, Brandon L], Mehta PK, Rifai LU, et al. Benefits of yoga for African American heart failure patients. Med Sci Sports Exerc. 2010;42:651-7.

[38] Pullen PR, Nagamia SH, Mehta PK, Thompson WR, Benardot D, Hammoud R, et al. Effects of yoga on inflammation and exercise capacity in patients with chronic heart failure. J Card Fail. 2008;14:407-13.

[39] Brown RP, Gerbarg PL. Sudarshan Kriya Yogic breathing in the treatment of stress, anxiety, and depression. Part II - clinical applications and guidelines. J Altern Complement Med. 2005;11:711-7. 
[40] Doria S, de Vuono A, Sanlorenzo R, Irtelli F, Mencacci C. Anti-anxiety efficacy of Sudarshan Kriya Yoga in general anxiety disorder: a multicomponent, yoga based, breath intervention program for patients suffering from generalized anxiety disorder with or without comorbidities. J Affect Disord. 2015;84:310-17.

[41] Toschi-Dias E, Tobaldini E, Solbiati M, Costantino G, Sanlorenzo R, Doria S, et al. Sudarshan Kriya Yoga improves cardiac autonomic control in patients with anxiety-depression disorders. J Affect Disord. 2017;214:74-80.

[42] Petersen JW, Felker GM. Inflammatory biomarkers in heart failure. Congest Heart Fail. 2006;12:324-8.

[43] Chin BS, Conway DS, Chung NA, Blann AD, Gibbs CR, Lip GY. Interleukin-6, tissue factor and von Willebrand factor in acute decompensated heart failure: relationship to treatment and prognosis. Blood Coagul Fibrinolysis. 2003;14:515-21.

[44] Harris TB, Ferrucci L, Tracy RP, Corti MC, Wacholder S, Ettinger WH Jr, et al. Associations of elevated interleukin-6 and C-reactive protein levels with mortality in the elderly. Am ] Med. 1999;106:506-12.

[45] Landmesser U, Merten R, Spiekermann S, Buttner K, Drexler H, Hornig B. Vascular extracellular superoxide dismutase activity in patients with coronary artery disease: relation to endothelium-dependent vasodilation. Circulation. 2000;101:2264-70.

[46] López-Otín C, Blasco MA, Partridge L, Serrano M, Kroemer G. The hallmarks of aging. Cell. 2013;153:1194-217.

[47] Hoeijmakers ]H. DNA damage, aging, and cancer. N Engl ] Med. 2009;361:1475-85.

[48] Lord C], Ashworth A. The DNA damage response and cancer therapy. Nature. 2012;481:287.

[49] Vijg ], Yousin S. Cenome Instability and Aging. Annu Rev Physiol. 2013;75:645-68.

[50] Moskalev AA, Shaposhnikov MV, Plyusnina EN, Zhavoronkov A, Budovsky A, Yanai H, et al. The role of DNA damage and repair in aging through the prism of Koch-like criteria. Ageing Res Rev. 2013;12:661-84.

[51] Burtner CR, Kennedy BK. Progeria syndromes and ageing: what is the connection? Nat Rev Mol Cell Biol. 2010;11:567.

[52] Kaszubowska L. Telomere shortening and ageing of the immune system. ] Physiol Pharmacol. 2008;59:169-86.

[53] Hornsby P]. Telomerase and the aging process. Exp Cerontol. 2007;42:575-81.

[54] Blackburn EH, Greider CW, Szostak JW. Telomeres and telomerase: the path from maize, Tetrahymena and yeast to human cancer and aging. Nat Med. 2006;12:1133-8.

[55] Jacobs TL, Epel ES, Lin ], Blackburn EH, Wolkowitz OM, Bridwell DA, et al. Intensive meditation training, immune cell telomerase activity, and psychological mediators. Psychoneuroendocrinology. 2011;36:664-81

[56] Jaskelioff M, Muller FL, Paik ]H, Thomas E, Jiang S, Adams AC, et al. Telomerase reactivation reverses tissue degeneration in aged telomerase-deficient mice. Nature. 2011;469:102-06.

[57] Palm W, De Lange T. How shelterin protects mammalian telomeres. Annu Rev Cenet. 2008;42:301-34.

[58] Walne A], Vulliamy T, Beswick R, Kirwan M, Dokal I. TINF2 mutations result in very short telomeres: analysis of a large cohort of patients with dyskeratosis congenita and related bone marrow failure syndromes. Blood. 2008;112:3594-600.

[59] Zhong F, Savage SA, Shkreli M, Giri N, Jessop L, Myers T, et al. Disruption of telomerase trafficking by TCAB1 mutation causes dyskeratosis congenita. Genes Dev. 2011;25:11-6.

[60] Tolahunase M, Sagar R, Dada R. Impact of Yoga and meditation on cellular aging in apparently healthy individuals: a prospective, openlabel single-arm exploratory study. Oxid Med Cell Longev. 2017;2017:7928981.

[61] Kumar SB, Yadav R, Yadav RK, Tolahunase M, Dada R. Telomerase activity and cellular aging might be positively modified by a yogabased lifestyle. J Altern Complement Med. 2015;21:370-72.

[62] Lavretsky H, Epel ES, Siddarth P, Nazarian N, Cyr NS, Khalsa DS, et al. A pilot study of yogic meditation for family dementia caregivers with depressive symptoms: effects on mental health, cognition, and telomerase activity. Int $]$ Ceriatr Psychiatry. 2013;28:57-65.

[63] Krishna BH, Keerthi CS, Kumar CK, Reddy NM. Association of leukocyte telomere length with oxidative stress in yoga practitioners. J Clin Diagn Res. 2015;9:CCO1-3. 